\title{
Reintroducing Dyslexia: Early Identification and Implications for Pediatric Practice
}

\author{
Joseph Sanfilippo ${ }^{\mathrm{a}, \mathrm{b}}$, Molly Ness ${ }^{\mathrm{c}}$, Yaacov Petscher $^{\mathrm{d}}$, Leonard Rappaport ${ }^{\mathrm{a}, \mathrm{e}}$, Barry Zuckerman $^{\mathrm{f}, \mathrm{g}}$, \\ \& Nadine $\mathrm{Gaab}^{\mathrm{a}, \mathrm{e}, \mathrm{h}}$
}

\begin{abstract}
Affiliations: 'Division of Developmental Medicine, Boston Children's Hospital, Boston, Massachusetts; ${ }^{b}$ Queen's University School of Medicine, Kingston, Ontario; ${ }^{~}$ Fordham University Graduate School of Education, New York, New York; ${ }^{\mathrm{d}}$ Florida Center for Reading Research, Florida State University, Tallahassee, Florida; ${ }^{\mathrm{e} D e p a r t m e n t ~ o f ~ P e d i a t r i c s, ~ H a r v a r d ~}$ Medical School, Boston, Massachusetts; ${ }^{\mathrm{f} D e p a r t m e n t}$ of Pediatrics, Boston University School of Medicine, Boston, Massachusetts; ${ }^{\circ}$ Boston Medical Center, Boston, Massachusetts; and ${ }^{\text {hHarvard }}$ Graduate School of Education, Cambridge, Massachusetts.
\end{abstract}

Corresponding Author: Nadine Gaab, Division of Developmental Medicine, Boston Children's Hospital, 1 Autumn Street (Office 643), Boston MA ,02215, nadine.gaab@childrens.harvard.edu, 857-218-3021.

Funding Source: This work was funded by the National Institutes of Health (NIH) grant number R01 HD065762.

Financial Disclosure: The authors have no financial relationships relevant to this article to disclose.

Conflict of Interest: Nadine Gaab and Yaacov Petscher are developers of the Boston Early Literacy Screener. The other authors have no potential conflicts of interest to disclose. 


\begin{abstract}
Dyslexia is a common learning disability that renders children susceptible to poor health outcomes and many elements of socioeconomic difficulty. It is commonly undiagnosed until a child has repeatedly failed to learn to read in elementary school; this late diagnosis not only puts the child at an academic disadvantage, but also can be a precursor to psychiatric comorbidities such as anxiety and depression. Genetic and neuroimaging research have demonstrated that dyslexia is heritable and that it is undergirded by brain differences that are present even before reading instruction begins. Cognitive-behavioral research has revealed that there are early literacy skill deficits that represent red flags for dyslexia risk and can be measured at a preschool age. Altogether, this evidence points to dyslexia as a disability that can be flagged by a pediatrician prior to school entry, during a period of heightened brain plasticity when interventions are more likely to be effective. In this review, we discuss the clinical implications of the most recent advances in dyslexia research, which converge to indicate that early identification and screening are crucial to the prevention or mitigation of adverse secondary consequences of dyslexia. We further highlight evidence-based and practical strategies for the implementation of early risk identification in pediatric practice so that physicians can be empowered in their ability to treat, educate, and advocate for their patients and families with dyslexia.
\end{abstract}




\section{Introduction}

The development of reading proficiency in childhood is a public health issue: literacy is a widely recognized determinant of health outcomes and is associated with many indices of academic, social, vocational, and economic success ${ }^{1}$. A recent National Academy of Medicine summary highlights that duration of education, which is highly dependent on reading proficiency, is a better predictor of health and long life than cigarette smoking or obesity ${ }^{2}$. Children skilled in reading go on to perform better in school, attain higher levels of education, experience lower rates of disease, are less likely to be incarcerated or experience poverty, are more likely to find employment, and achieve higher average incomes as adults compared to children who fail to achieve reading proficiency ${ }^{3}$. For many children with reading impairments, however, the process of learning to read is rife with struggle and frustration, and these children are left susceptible to adverse secondary outcomes, including anxiety and depression. A neurobiologically-based specific learning disability, dyslexia, affects $5-10 \%$ of children ${ }^{4,5}$ and is a persistent barrier to reading acquisition.

Dyslexia - or word-level reading difficulty ${ }^{6}-$ is often characterized by a core deficit in phonological processing (the ability to recognize and manipulate speech sounds), which results in impairments in word recognition, spelling, and decoding (the ability to 'sound out' words) ${ }^{7}$. These impairments almost always lead to difficulties in reading fluency and comprehension, reduced vocabulary, lower content knowledge ${ }^{8}$, and a decline in overall school performance ${ }^{9}$. Dyslexia cannot be explained by poor hearing or vision, low language enrichment, or lack of motivation or opportunity ${ }^{10}$. According to the DSM-5, dyslexia is a clinical term falling under the umbrella of "specific learning disorder that impedes the ability to learn or use specific academic skills (e.g., reading, writing, or arithmetic)"11. 
Although there are many negative outcomes associated with dyslexia, particularly salient to the pediatrician is the association between dyslexia and poor mental health ${ }^{12,13}$. Children with dyslexia are more likely to suffer from generalized anxiety ${ }^{14,15}$ and also exhibit higher rates of depression ${ }^{14,16}$. Because screening for dyslexia is not routinely performed, the direction of causation between dyslexia and comorbid mood disorders in each case is unclear, and this uncertainty can preclude effective upstream treatment. A mood disorder may be identified in a child with unidentified comorbid dyslexia when it is the dyslexia that is antecedent and causative, obscuring the primary target for intervention.

In addition to mood disorders, speech and language problems are frequently comorbid with dyslexia, as both dyslexia and developmental language disorders can be characterized by poor phonology ${ }^{17-19}$ as well as language deficits beyond the phonological domain (e.g., oral language comprehension $)^{20}$. Indeed, about half of children identified with dyslexia have language disorders, and about half of children with language disorders have dyslexia ${ }^{20}$. Importantly, speech and language problems commonly precede problems in learning to read, so reports from speech and language pathologists indicating speech and language problems can represent red flags for dyslexia in young children ${ }^{21}$.

There are many other developmental and psychiatric conditions that are frequently comorbid with dyslexia, further jeopardizing these children's health and academic outcomes. 20$40 \%$ of children with ADHD have dyslexia ${ }^{22}$, and children with autism spectrum disorder are also at increased risk of having dyslexia ${ }^{23}$, although it can be difficult to differentiate between true comorbidity and symptom overlap with ASD. Other behavioral disorders such as conduct disorder and oppositional defiant disorder are also associated with dyslexia ${ }^{24}$. Additionally, as many as $85 \%$ of children with dyspraxia (developmental coordination disorder) have dyslexia ${ }^{25}$, and children 
with dyscalculia (math learning disability) are more likely to have dyslexia than those without dyscalculia ${ }^{26}$. Knowledge of dyslexia within pediatric practice is therefore paramount in considering the most appropriate treatments for these many coexisting disorders.

Despite increasing collaboration among educators, physicians, neuroscientists, speech and language pathologists, and psychologists, dyslexia is often overlooked in the field of general pediatrics, perhaps because the diagnostic label of dyslexia is not often used in practice, having been replaced largely by education language of strengths and weaknesses. The clinical implications of a reluctance to use dyslexia as a diagnostic label include children failing to receive adequate attention to early signs of risk, appropriate interventions in school, and mental health support from child health clinicians. The goal of this article is to provide an up-to-date overview of dyslexia; specifically, we address common knowledge gaps, highlight its neurobiological underpinnings, and outline ways in which pediatricians can play an active role in the early identification of dyslexia risk to facilitate literacy development and prevent secondary behavioral and mental health problems.

\section{The Etiology of Dyslexia}

The etiology of dyslexia is multifaceted, including genetic, perceptual/cognitive, neurobiological, and environmental factors ${ }^{9}$. Dyslexia is strongly heritable, occurring in up to $68 \%$ of identical twins of individuals with dyslexia and up to 50\% of individuals who have a first degree relative with dyslexia ${ }^{27-30}$. Several genes ${ }^{31-33}$ (e.g., ROBO1, DCDC2, DYX1C1, KIAA0319) have been reported to be candidates for dyslexia susceptibility; it is thought that most of these genes play a role in early brain development $t^{34-38}$. 
Furthermore, various studies have shown atypical brain characteristics in children and adults with dyslexia compared to their peers ${ }^{39}$. Functional MRI studies indicate that reading for typical readers takes place predominantly in left-hemispheric sites of the brain, including the inferior frontal, superior temporal, temporo-parietal, and occipito-temporal cortices ${ }^{40}$. As a group, individuals with dyslexia show hypoactivation in the left-hemisphere reading systems ${ }^{41}$. The structural and functional atypicalities in these brain regions include reduced gray matter volume $\mathrm{e}^{42}$, hypoactivation in response to reading-related fMRI tasks ${ }^{43}$, and weaker functional connectivity between key areas of the reading network ${ }^{44}$. Importantly, differences in brain structure and function characteristic of dyslexia can be observed in children prior to the start of formal reading instruction, indicating that dyslexia does not result from a struggle to learn to read but rather represents a biological disposition present at the preschool age or perhaps as early as infancy ${ }^{45-47}$. Altogether, these findings suggest that children predisposed to dyslexia enter their first day of school with a brain that is less equipped to learn to read.

It is worth noting that reading proficiency is strongly associated with socioeconomic status $^{48-50}: 80 \%$ of fourth grade students from low socioeconomic backgrounds read below gradelevel proficiency ${ }^{51}$. In particular, children with inadequate exposure to language are more likely to struggle with reading ${ }^{52}$. Although these children do not necessarily meet a diagnosis of dyslexia, children who struggle with reading, regardless of etiology, have been shown to suffer the same adverse health and psychosocial consequences and benefit from interventions that have been primarily developed to address deficits associated with dyslexia ${ }^{53-55}$. Indeed, socioeconomic disadvantages can affect brain development, further obscuring the boundary between biological and environmental determinants of dyslexia ${ }^{56}$. Thus, the early recognition of socioeconomic and 
other environmental risk factors (e.g. stress and other measures of adversity) can be crucial components of a clinical assessment of a child suspected to be at risk for dyslexia.

The classical Simple View of Reading posits that skilled reading involves at least two major cognitive components: word recognition (including decoding and phonological awareness) and language comprehension (e.g., knowledge of vocabulary and language structures); together, these strands coalesce to form what is classically known as the 'reading rope' ${ }^{\text {' }}$. Although the Simple View of Reading has been borne out by evidence ${ }^{58}$, its components are not single entities but are multifactorial, malleable, and context-dependent - especially language comprehension and cannot be captured in a single assessment ${ }^{59}$. Furthermore, recent research has found that skilled reading, especially in older children, is contingent upon knowledge of academic language and the additional cognitive skills of perspective-taking and reasoning ${ }^{60}$.

Dyslexia is related to deficits in one or more strands of the reading rope, and particularly to early struggles in oral language ${ }^{61}$; an important precursor of dyslexia is deficits in phonological/phonemic awareness. Other predictors include struggles in letter-sound correspondence, pseudoword repetition (the ability to pronounce spoken nonsense words), identifying rhyming sounds, rapid automatized naming (the ability to automatically retrieve the names of objects, letters, or colors), and deficits in oral language comprehension and receptive and expressive vocabulary ${ }^{62}$. These key linguistic and pre-literacy measures can be assessed in children as young as four years old, and that they can serve as crucial markers in identifying children at risk

for dyslexia or other reading impairments ${ }^{63-65}$. Some of these literacy precursors measured in kindergarten have been shown to predict reading comprehension in the tenth grade ${ }^{66}$.

\section{The Dyslexia Paradox and the Risks of Delayed Diagnosis}


Many children with dyslexia are diagnosed long after they demonstrate recognizable struggles with pre-literacy milestones ${ }^{67}$. Currently, children are typically diagnosed at the end of second or beginning of third grade (and many much later), after they have already failed to learn to read over a long period of time and have fallen behind their peers academically ${ }^{68}$. This wait-tofail approach fails to capitalize on the most effective window for intervention, which is during an earlier period of heightened brain plasticity in kindergarten and first grade ${ }^{68}$. Referred to as the 'dyslexia paradox ${ }^{92}$, the gap between the earliest time at which identification is possible and the time at which identification and treatment typically occur can preclude effective intervention and has profound academic and socioemotional implications for the developing child. Children at the $10^{\text {th }}$ percentile of reading ability may read as many words in one year as a child at the $90^{\text {th }}$ percentile reads in two days ${ }^{69}$. Because reading becomes the expected vehicle for content learning as children progress through the school system, it is imperative that children with dyslexia are identified early and receive intervention without delay. When at-risk beginning readers receive intensive early reading intervention, $56 \%$ to $92 \%$ of these children achieve average reading ability ${ }^{70}$.

In addition to the poor academic outcomes associated with untreated dyslexia, diagnosing children after a prolonged period of failure can have severe implications for children's mental health, as discussed. Often perceived as lazy or labeled as 'stupid', children with dyslexia may develop decreased self-esteem which can progress to anxiety and depression ${ }^{71}$. Furthermore, children with learning disabilities are less likely to complete high school ${ }^{72}$, less likely to attend programs of higher education ${ }^{73}$, and at increased risk of entering the juvenile justice system: 28 $45 \%$ of incarcerated youth have a learning disability ${ }^{74}$, as well as $20-30 \%$ of incarcerated adults ${ }^{75}$. Additionally, adults with learning disabilities are more likely to be unemployed and, on average, earn annual incomes well below the national average ${ }^{5}$. Given the prognostic benefit of early 
diagnosis and intervention, and the many adverse consequences that can be avoided or mitigated, there is great potential therapeutic value in identifying early risk for dyslexia in the pediatric clinic.

\section{The Role of Pediatricians and their Professional Organizations in Dyslexia Risk Screening}

It is important to distinguish between screening for dyslexia risk and diagnosing dyslexia. Screening refers to a brief assessment that determines the risk of having or developing dyslexia, which can be undertaken at an early age, prior to school entry ${ }^{76,77}$. Conversely, a formal diagnosis can only occur after reading instruction has begun and requires a more comprehensive neuropsychological evaluation which can be motivated by a prior screening result ${ }^{78}$. While attention to both screening and diagnosis is vital in ensuring that the appropriate interventions are implemented for the child, screening for risk of dyslexia is possible earlier in the developmental time course than is diagnosis, and thus it represents an opportunity for expeditious upstream intervention.

The consideration of any screening regimen requires that a valid and acceptable test be available, that an effective and accessible means of treatment be available, and that the potential benefits of screening outweigh the risks ${ }^{79}$ without an undue burden to the practitioner or patient. In the case of dyslexia, screening children individually for risk can be accomplished quickly and inexpensively through a consideration of family history and through short behavioral assessments of early literacy abilities, which are strong predictors of later reading difficulty; extensive evidence has demonstrated the benefit of early evidence-based response to screening ${ }^{68,80,81}$; and the risks of implementing a screening process are minimal to negligible. A review of a child's family history of dyslexia is a worthwhile start to the process of early identification: a positive family history 
necessitates screening, close monitoring, and/or referral, while a negative family history still requires a level of ongoing observation.

The risk of a false positive result is present with any screening program, and in the case of dyslexia screening, the risk is tantamount to further evaluation, monitoring, and educational supports. Although these processes do place demands on the child and represent cost and effort on the part of practitioners, the burden of failing to identify these children early is ultimately greater than the burden of providing supplemental resources to a child needlessly. With time, the risk of false positives and false negatives can be expected to diminish with the continuous development of new screening instruments with increased specificity and sensitivity.

With the recognition that early literacy predictors of dyslexia can be identified before the start of kindergarten ${ }^{82}$, we can no longer afford to wait for screenings in children's first formal schooling experiences. In a 2009 position paper negating visual deficiencies as the origin of dyslexia, the American Academy of Pediatrics stated that "pediatrics should be vigilant in looking for early signs of evolving learning disabilities" ${ }^{\prime 2}$. Given the existing role of the pediatrician in monitoring the development of children prior to school-age, during a period when the support of language and literacy development is vital, pediatricians have the opportunity to implement early literacy screenings in well-child visits.

Pediatricians can contribute to a collaborative effort to screen for children at risk by capitalizing on their unique role in a child's early developmental trajectory and by taking advantage of their network of health and educational resources. It is important to note that many parents desire this proactive stance from their child's health care provider: more than one-third of surveyed parents indicated that they have not discussed reading with their pediatrician; nearly half of that group believed such conversations would be useful ${ }^{84}$. Pediatricians can also provide 
referrals to outside experts, such as neuropsychologists and speech and language pathologists, and communicate with patients' schools ${ }^{85}$.

Pediatricians typically rely on a developmental milestone checklist in evaluating a child's development in various domains, however recent research demonstrates that there is great variability between the many available checklists, both in content and in milestone age ranges ${ }^{86}$. Furthermore, while these checklists do account for receptive and expressive language, they do not include a comprehensive inventory of key early literacy measures that are crucial for assessing for dyslexia risk.

Early warning signs of dyslexia may be visible prior to school entry, and thus the pediatrician may be a child's first health or educational professional capable of identifying these signs and implementing a management plan. Pediatricians can document the extent to which a child can recite common nursery rhymes, recognize rhyming sounds, report the sound that a letter makes, and use correct and age-appropriate pronunciation and vocabulary. It is important to note that phonological deficits can present differently in different children, and children with dyslexia will vary in the specific tasks with which they show difficulty. Thus, screenings serve to pinpoint particular early literacy skills that may require remedial attention and also identify children who may eventually require a more detailed evaluation in order to come to a definitive diagnosis of dyslexia.

\section{A More Proactive Approach: Screening and Advocacy}

There are many methods by which pediatricians can work towards systematic early identification of dyslexia in their practices. As mentioned, pediatricians should elicit a family history of dyslexia, recognize assessments done by schools that indicate a risk/diagnosis, and 
include dyslexia in the differential diagnosis for low self-esteem, depression, anxiety, or disruptive behaviors. The governing bodies of associations of pediatricians should provide training on dyslexia assessments and interventions as part of ongoing continuing education so that pediatricians can become adept at implementing screening processes and at interpreting, monitoring, and responding efficiently to evaluations and interventions performed outside the clinic. This training should also involve the appropriate referral to outside consultants and interventionists when needed. Given the high overlap between dyslexia and deficits in speech and language, physicians should consider referring children who are at risk for dyslexia to a speech and language pathologist who is trained in early literacy ${ }^{21}$. Furthermore, pediatric associations can partner with dyslexia researchers and education specialists to create educational resources and training that can assist pediatricians in providing education and support to their patients and families with dyslexia.

Checklists, questionnaires, and interviews pertaining to key risk factors can be completed in conjunction with a child's parent to gather a rudimentary idea of a child's risk. It is important to note that while these methods provide a quick account of a child's risk, they are often tools that are not scientifically validated and are thus intended for a preliminary, formative assessment. Rigorously validated screeners comprising of child-centered behavioral assessments provide the most reliable and unbiased testament of a child's risk status, and they should be considered the gold standard for screening.

Pediatric clinics could consider hosting 'screening days' with a literacy focus that can aim to simultaneously screen for early predictors of dyslexia while also facilitating a literacy-rich environment by making literacy materials (e.g., board books) available to families. Many pediatricians have already made great strides in promoting literacy within their clinics. The Reach 
Out and Read program, which has seen thousands of physicians in primary care clinics across the United States distribute books to millions of patients, has been effective in facilitating language and pre-literacy skills in children ${ }^{87}$. A similar program with an additional screening component could be even more beneficial in supporting bourgeoning literacy while also identifying those children at risk for dyslexia.

The National Center for Learning Disabilities has created a checklist tool for learning disabilities that can identify signs of risk among children of different age groups, including children as young as in preschool ${ }^{88}$. While not specific to dyslexia, this tool can be implemented to systematically identify risk factors for learning disability among preschool children, such as poor retention of new vocabulary and trouble with letter naming. A checklist such as this one could feasibly be completed by the child's caregiver in the waiting room and reviewed and followed-up as appropriate by the physician.

A further possibility is the use of a standardized, brief two- or three-question first-step questionnaire, the likes of which have already been demonstrated to be successful in pre-screening other conditions like depression ${ }^{89}$ and $\mathrm{ADHD}^{90}$. Pediatricians can pose questions to a preschool child's caregiver(s) pertaining to key risk factors for dyslexia. Affirmative answers to these firststep questions can lead to a more detailed, validated screening tool that can be used to identify specific deficits present. Furthermore, there are tablet- and smartphone-based gamified and selfadministered screening tools currently being developed that will be able to be purchased inexpensively by the clinic or by the patient's caregiver. These and other innovative tools, such as children's storybooks accompanied by scripted scoring forms, continue to be designed and validated for use in quickly measuring emergent literacy skills in preschool-age children in the pediatric clinic $^{91}$. These tools are being designed to be entertaining for the child and will be 
informative to the clinician in determining appropriate next steps and referrals for further evaluation and intervention.

As new screening tools continue to become available in the coming years, it will be important for practitioners to be knowledgeable about the characteristics of an appropriate dyslexia screener and to be discerning in their selection. The ideal screener has been validated in a representative sample; has strong evidence for reliability, validity, and classification accuracy; has developmentally appropriate content given the age or grade-level of the child; and has the capacity to measure both word recognition and linguistic comprehension ${ }^{76}$. A comprehensive list of available dyslexia screening tools, along with an indication of their fulfillment of characteristics like those listed above, is presently available for practitioners to consult (see ${ }^{92}$ ). An additional resource for practitioners is the What Works Clearinghouse, which provides evidence-based evaluations on literacy screening products as they become available ${ }^{93}$.

In addition to child-directed assessments, given the strong heritability of dyslexia, a crucial component of early identification is an assessment of the reading history of the child's parent(s) to determine the child's familial risk. Family history is both quick to elicit and informative in the global assessment of a child's risk. The Adult Reading History Questionnaire (ARHQ) is a validated inventory $^{94}$ of an adult's literacy abilities and habits and, when completed, presents a score that indicates the adult's risk of having dyslexia (see ${ }^{95}$ for a digital version of the questionnaire). Follow-up questions should be presented to a parent with a high-risk score in order to rule out an environmental explanation for reading impairment (e.g., lack of formal reading instruction) as opposed to a true disability. This distinction is particularly important to consider in communities with considerable immigrant populations, who may be flagged by the ARHQ as 'at risk' but simply because they are adult learners of the dominant language. This parent inventory 
is useful not only because it can indicate a child's possible familial risk, but also because it can reveal less literacy-rich home environments that leave children with insufficient literacy materials and support, illuminating additional targets for intervention.

Beyond the clinic, the medical community can be vocal advocates in national conversations about dyslexia, many of which are currently happening in state legislations; as of now, only seven U.S. states lack state-level legislation focusing on early screening, teacher training, and/or instructional support (for a comprehensive overview of state legislation, see ${ }^{96}$ ). Despite such recent attention, there is much room for growth in pediatric neurocognitive research funding, which has lagged compared to adult neurocognitive disorders. Increased funding and research must explore etiological models, examine comorbid relationships, refine tools for the early identification of children at risk for dyslexia and other reading impairments, investigate additional tools that that may be of use for children for whom English is not their first language, and develop and evaluate intervention strategies and their effectiveness. A first order goal should be the development of screening guidelines and tools for use during pediatric visits for four- and five-year-old children that identify children at risk during a time of heightened brain plasticity, when an optimal window exists for early interventions, while also refining guidelines to identify older children who were not screened earlier. Finally, with the help of policymakers, the current 'failure' model of dyslexia must be replaced with a 'support' model that enables school-, clinic-, and community-based early screenings and subsequent evidence-based response to screening through empowered and welltrained teachers within the general education framework. Physicians can be powerful agents of these positive changes, both at the level of their clinical practices and as advocates in their communities and beyond. 


\section{Conclusion}

Our current knowledge of the neurobiological basis for dyslexia, its reliable developmental-behavioral predictors, the effectiveness of early intervention, and the myriad adverse effects of reading failure demand that a proactive, preventive approach (instead of a deficit-driven approach) be taken to identifying and treating children at risk. Early identification should start with an assessment of family history and followed with validated behavioral screening tools. With time, new and innovative formats for screening will emerge. In acknowledging the significant effort devoted by pediatricians to screening various conditions, the future will require a consideration of novel approaches to office visits or increased community-based collaboration with preschools to accomplish screening for disorders which, like dyslexia, are of nontrivial prevalence and are associated with available and effective interventions. Pediatricians occupy a unique role in the lives of children such that they are well-positioned to recognize and respond to risk factors for dyslexia even before children enter the education system, however the delivery of dyslexia interventions is and will largely continue to be implemented outside the scope of the pediatrician's practice. Thus, the contributions of both pediatricians and other health and educational professionals are crucial to optimizing the process of identifying and treating dyslexia. While the response to dyslexia screening and intervention is multifaceted and longitudinal, the trajectory of children's literacy outcomes has the potential to be improved through the implementation of early identification in pediatric practice. 


\section{References}

1. Irwin LG, Siddiqi A, Hertzman C. Early child development: A powerful equalizer: Final report for the World Health Organization's commission on the social determinants of health. Vancouver, BC: Human Early Learning Partnership; 2007.

2. Johnston RBJ. Poor education predicts poor health -- A challenge unmet by American medicine. NAM Perspectives. 2019.

3. Cree A, Kay A, Steward J. The economic and social cost of illiteracy: A snapshot of illiteracy in a global context. Melbourne, Australia: World Literacy Foundation; 2012.

4. $\quad$ Shaywitz S. Dyslexia. New England Journal of Medicine. 1998;338(5):307-312.

5. Cortelia C, Horowitz SH. The state of learning disabilities: Facts, trends and emerging issues. New York, NY: National Center for Learning Disabilities; 2014.

6. Fletcher J, Lyon GR, Fuchs L, Barnes M. Learning disabilities: From identification to intervention. New York, NY: Guilford Press; 2018.

7. Vellutino FR, Fletcher J, Snowling M, Scanlon DM. Specific reading disability (dyslexia): What we have learned in the past four decades? Journal of Child Psychology and Psychiatry. 2004;45(1):2-40

8. Stanovich K. Matthew effects in reading: Some consequences of individual differences in the acquisition of literacy. Reading Research Quarterly. 1986;21(4):360-407.

9. Ozernov-Palchik O, Yu X, Wang Y, Gaab N. Lessons to be learned: How a comprehensive neurobiological framework of atypical reading development can inform educational practice. Current Opinion in Behavioral Sciences. 2016;10:45-58.

10. Moats L, Dakin KE. Basic facts about dyslexia and other reading problems. Baltimore, MD: The International Dyslexia Association; 2008.

11. Petretto DR, Masala C. Dyslexia and Specific Learning Disorders: New International Diagnostic Criteria. Journal of Childhood \& Developmental Disorders. 2017;3(4):1-5.

12. Hendren R, Haft SL, Black J, White N, Hoeft F. Recognizing psychiatric comorbidity with reading disorders. Frontiers in Psychiatry. 2018;9.

13. Grills-Taquechel AE, Fletcher JM, Vaughn SR, Stuebing KK. Anxiety and reading difficulties in early elementary school: Evidence for unidirectionalor bi-directional relations? Child Psychiatry and Human Development. 2012;43(1):35-47.

14. Mammarella I, Ghisi M, Bomba M, et al. Anxiety and depression in children with nonverbal learning disabilities, reading disabilities, or typical development. Journal of Learning Disabilities. 2016;49(2):130-139.

15. Nelson JM, Harwood H. Learning disabilities and anxiety: A meta-analysis. Journal of Learning Disabilities. 2011;44(1):3-17.

16. Mugnaini D, Lassi S, La Malfa G, Albertini G. Internalizing correlates of dyslexia. World Journal of Pediatrics. 2009;5(4):255-264.

17. Bishop DV, Snowling MJ. Developmental dyslexia and specific language impairment: Same or different? Psychological Bulletin. 2004;130:858-886.

18. Gooch D, Hulme C, Nash H.M., Snowling MJ. Comorbidities in preschool children at risk of dyslexia: The role of language ability. Journal of Child Psychology and Psychiatry. 2013;55:237-246.

19. Snowling MJ, Melby-Lervag M. Oral language deficits in familial dyslexia: A metaanalysis and review. Psychological Bulletin. 2016;142:498-545. 
20. Adlof SM, Hogan TP. Understanding dyslexia in the context of developmental language disorders. Language, Speech, and Hearing Services in Schools. 2018;49(4):762-773.

21. Cabbage KL, Farquharson K, Iuzzini-Seigel J, Zuk J, Hogan TP. Exploring the overlap between dyslexia and speech sound production deficits. Language, Speech, and Hearing Services in Schools. 2018;49(4):774-786.

22. Germano E, Gagliano A, Curatolo P. Comorbidity of ADHD and dyslexia. Developmental Neuropsychology. 2010;35(5):475-493.

23. Asberg J, Kopp S, Berg-Kelly K, Gillberg C. Reading comprehension, word decoding and spelling in girls with autism spectrum disorders (ASD) or attendiondeficit/hyperactivity disorder (ADHD): performance and predictors. International Journal of Language \& Communication Disorders. 2010;45(1):61-71.

24. Burke JD, Loeber R, Birmaher B. Oppositoinal defiant disorder and conduct disorder: A review of the past 10 years, part II. Journal of the American Academy of Child and Adolescent Psychiatry. 2002;41(11):1275-1293.

25. Pauc R. Comorbidity of dyslexia, dyspraxia, attention deficit disorder (ADD), attention deficit hyperactive disorder (ADHD), obsessive compulsive disorder (OCD) and Tourette's syndrome in children: A prospective epidemiological study. Clinical Chiropractic. 2005;8:189-198.

26. Moll K, Landerl K, Snowling MJ, Schulte-Koerne E. Understanding comorbidity of learning disorders: Task-dependent estimates of prevalence. Journal of Child Psychology and Psychiatry. 2018;60(3):286-294.

27. Snowling MJ, Melby-Lervag M. Oral language deficits in familial dyslexia: A metaanalysis and review. Psychological Bulletin. 2016;142:498-545.

28. Finucci JM, Whitehouse CC, Isaacs SD, Childs B. Derivation and validation of a quantitative definition of specific reading disability for adults. Developmental Medicine \& Child Neurology. 1984;26(2):143-153.

29. Volger GP, DeFries JC, Decker SN. Family history as an indicator of risk for reading disability. Journal of Learning Disabilities. 1985;18(7):419-421.

30. Grigorenko EL. Speaking genes or genes for speaking? Deciphering the genetics of speech and language. Journal of Child Psychology Psychiatry. 2009;50(1-2):116-125.

31. Galaburda AM, LoTurco J, Ramus F, Fitch RH, Rosen GD. From genes to behavior in developmental dyslexia. Nature Neuroscience. 2006;9(10):1213-1217.

32. Paracchini S, Scerri T, Monaco AP. The genetic lexicon of dyslexia. Annual Review of Genomics and Human Genetics. 2007;8:57-79.

33. Mascheretti S, Riva V, Giorda R, et al. KIAA0319 and ROB01: Evidence on association with reading and pleiotropic effects on language and mathematics abilities in developmental dyslexia. Journal of Human Genetics. 2014;59(4):189-197.

34. Galaburda AM, LoTurco J, Ramus F, Fitch RH, \& Rosen GD. From genes to behavior in developmental dyslexia. Nature Neuroscience. 2006;9(10):1213-1217.

35. Hannula-Jouppi K, Kaminem-Ahola N, Taipale M, et al. The axon guidance receptor gene ROBO1 is a candidate gene for developmental dyslexia. PLoS Genetics 2005;1(4):e50.

36. Meng H, Smith SD, Hager K, et al. DCDC2 is associated with reading disability and modulates neuronal development in the brain. Proceedings of the National Academy of Sciences of the United States of America. 2005;102(47):17053-17058. 
37. Paracchini S, Thomas A, Castro S, et al. The chromosome 6p22 haplotype associated with dyslexia reduces the expression of KIAA0319, a novel gene involved in neuronal migration. Human Molecular Genetics. 2006;15(10):1659-1666.

38. Skiba T, Landi, N., Wagner, R., \& Grigorenko, E. L. . In search of the perfect phenotype: an analysis of linkage and association studies of reading and reading-related processes. Behavior Genetics. 2011;41(1):6-30.

39. Richlan F, Kronbichler M, Wimmer H. Meta-analyzing brain dysfunctions in dyslexic children and adults. NeuroImage. 2011;56(3):1735-1742.

40. Martin A, Schurz M, Kronbichler M, Richlan F. Reading in the brain of children and adults: a meta-analysis of 40 functional magnetic resonance imaging studies. Human Brain Mapping. 2015;36(5):1963-1981.

41. Peterson RL, Pennington BF. Developmental dyslexia. Lancet. 2012;379(9830):19972007.

42. Linkersdorfer J, Lonnemann J, Lindberg S, Hasselhorn M, Fiebach CJ. Grey Matter Alterations Co-Localize with Functional Abnormalities in Developmental Dyslexia: An ALE Meta-Analysis. PLoS One. 2012;7(8):e43122.

43. Richlan F, Kronbichler M, Wimmer H. Functional abnormalities in the dyslexic brain: a quantitative meta-analysis of neuroimaging studies. Human Brain Mapping. 2009;30(10):3299-3308.

44. Horwitz B, Rumsey JM, Donohue BC. Functional connectivity of the angular gyrus in normal reading and dyslexia. Proceedings of the National Academy of Sciences in the United States of America. 1998;95(15):8939-8944.

45. Langer N, Peysakhovich B, Zuk J, Drottar M, Silva D, Smith S, Becker B, Grant PE, Gaab N. White matter alterations in infants at risk for developmental dyslexia. Cerebral Cortex. 2017;27(2):1027-1036.

46. Leppanen PH, Hamalainen JA, Guttorm TK, et al. Infant brain responses associated with reading-related skills before school and at school age. Clinical Neurophysiology. 2012;42(1-2):35-41.

47. Im K, Raschle NM, Smith SA, Grant PE, Gaab N. Atypical Sulcal Pattern in Children with Developmental Dyslexia and At-Risk Kindergarteners. Cerebral Cortex. 2015;26(3):1138-1148.

48. Peterson RL, Pennington BF. Developmental dyslexia. Annual Review of Clinical Psychology. 2015;11:283-307.

49. Reardon SF. The widening academic achievement gap between the rich and the poor: New evidence and possible explanations. In: Murnane R, Duncan G, eds. Whither Opportunity?Rising Inequality, Schools, and Children's Life Chances. New York, NY: Russell Sage Foundation Press; 2011:91-116.

50. Noble KG, McCandliss BD. Reading development and impairment: behavioral, social, and neurobiological factors. Journal of Developmental Behavioral Pediatrics. 2005;26(5):370-378.

51. National Center for Education Statistics (NCES). National Assessment of Educational Progress (NAEP): 1992, 1994, 1998, 2000, 2002, 2003, 2005, 2007, 2009, 2011, 2013, 2015, and 2017 Reading Assessments. 2017; https://nces.ed.gov/nationsreportcard/naepdata/. Accessed August 1, 2019. 
52. Metsala JL. Lexical reorganization and the emergence of phonological awareness. In: Neuman SB, Dickinson DK, eds. Handbook of Early Literacy Research Vol 3. 2011:6682.

53. Kilpatrick DA. Genetics, the environment, and poor instruction as contributors to worklevel reading difficulties: Does it matter for early identification and instruction? Perspectives on Language and Literacy. 2018;44(3):25-28.

54. National Institute of Child Health and Human Development. Report of the National Reading Panel. Teaching children to read: an evidence-based assessment of the scientific research literature on reading and its implications for reading instruction. 2000; http://www.nichd.nih.gov/publications/nrp/upload/smallbook_pdf.pdf. Accessed August $1,2019$.

55. Foorman BR. Critical elements of classroom and small-group instruction promote reading success in all children. Learning Disabilities Research \& Practice. 2001;16(4):203-212.

56. Noble KG, Wolmetz ME, Ochs LG, Farah MJ, McCandliss BD. Brain-behavior relationships in reading acquisition are modulated by socioeconomic factors. Developmental Science. 2006;9(6):642-654.

57. Scarborough HS. Connecting early language and literacy to later reading (dis)abilities: Evidence, theory, and practice. In: Neuman SB, Dickinson DK, eds. Handbook of early literacy research. New York: Guilford Press; 2001:97-110.

58. Lonigan CJ, Burgess SR, Schatschneider C. Examining the simple view of reading with elementary school chilren: Still simple after all these years. Remedial and Special Education. 2018;39(5):260-273.

59. Catts HW. The simple view of reading: Advancements and false impressions. Remedial and Special Education. 2018;39(5):317-323.

60. Snow C. Simple and Not-So-Simple Views of Reading. Remedial and Special Education. 2018;39(5):313-316.

61. Hulme C, Snowling M. Reading disorders and dyslexia. Pediatrics. 2016;28(6):731-735.

62. Ozernov-Palchik O, Gaab N. Tackling the 'dyslexia paradox': Reading brain and behavior for early markers of developmental dyslexia. Cognitive Science. 2016;7(2):156176.

63. Compton DL, Fuchs D, Fuchs LS, Bryant JD. Selecting at-risk readers in first grade for early intervention: A two-year longitudinal study of decision rules and procedures. Journal of Educational Psychology. 2006;98(2):394-409.

64. Puolakanaho A, Ahonen T, Aro M, et al. Very early phonological and language skills: estimating individual risk of reading disability. Journal of Child Psychology and Psychiatry. 2007;48(9):923-931.

65. Catts HW, Fey ME, Zhang X, Tomblin JB. Estimating the risk of future reading difficulties in kindergarten children: A research-based model and its clinical implementation. Language, Speech, and Hearing Services in Schools. 2001;32:38-50.

66. Stanley CT, Petscher Y, Catts H. A longitudinal investigation of direct and indirect links between reading skills in kindergarten and reading comprehension in tenth grade. Reading and Writing. 2018;31(1):133-153.

67. Torgesen JK. The prevention of reading difficulties Journal of School Psychology. 2002;40(1):7-26. 
68. Wanzek J, Vaughn S. Research-based implications from extensive early reading interventions. School Psychology Review. 2007;36(4):541.

69. Cunningham AE, Stanovich KE. What reading does for the mind. American Educator. 1998;22:8-15.

70. Torgesen JK. Lessons learned from research on interventions for students who have difficulty learning to read. In: McCardle P, Chhabra V, eds. The Voice of Evidence in Reading Research. Baltimore, MD: Paul H. Brookes Publishing Co.; 2004.

71. Mugnaini D, Lassi S, Malfa GL, Albertini G. Internalizing correlates of dyslexia. World Journal of Pediatrics. 2009;5(4):255-264.

72. Jilmerson S, Egeland B, Sroufe LA, Carlson B. A prospective longitudinal study of high school dropouts examining multiple predictors across development. Journal of School Psychology 2000;38:525-549.

73. Dougherty C. Numeracy, literacy and earnings: Evidence from the National Longitudinal Survey of Youth. Economics of Education Review. 2003;22(5):511-521.

74. Mallett CA, Stoddard-Dare P, Workman-Crenshaw L. Special education disabilities and juvenile delinquency: A unique challenge for school social work. School Social Work Journal. 2011;36(1):26-40.

75. Loucks N. Prisoners with learning difficulties and learning disabilities -- Review of prevalence and associated needs. London, UK: Prison Reform Trust: 2007.

76. Petscher Y, Fien H, Stanley C, et al. Screening for Dyslexia. National Center on Improving Literacy: 2019.

77. Gaab N. Reading impairments: Moving from a deficit-driven to a preventive model. 2019; https://bold.expert/identifying-risk-instead-of-failure/. Accessed August 1, 2019.

78. International Dyslexia Association. Dyslexia assessment: What is it and how can it help? 2017; https://dyslexiaida.org/dyslexia-assessment-what-is-it-and-how-can-it-help/. Accessed August 1, 2019.

79. Morabia A. History of medical screening: From concepts to action. Postgraduate Medical Journal. 2004;80(946):463-469.

80. Lovett MW, Frijters J, Wolf M, Steinbach KA, Sevcik R, Morris R. Early intervention for children at risk for reading disailities: The impact of grade at intervention and individual differences on intervention outcomes. Journal of Educational Psychology. 2017;109(7):889-914.

81. Catts HW, Nielsen D, Bridges M, Bontempo D, Liu Y. Early identification of reading disabilities within an RTI framework. Journal of Learning Disabilities. 2015;48(3):281297.

82. Puolakanaho A, Ahonen T, Aro M, et al. Very early phonological and language skills: Estimating individual risk of reading disability. Journal of Child Psychology and Psychiatry. 2007;48:923-931.

83. Lueder GT, Ruben JB, Blcoker RJ, et al. Joint statement: Learning disabilities, dyslexia, and vision. Pediatrics. 2009;124(2):837-44.

84. Kuo AA, Franke TM, Regalado M, Halfon N. Parent report of reading to young children. Pediatrics. 2004;113(6):1944-51.

85. Schulte E. Learning disorders: How pediatricians can help. Cleveland Clinic Journal of Medicine. 2015;82:24-28.

86. Wilkinson CL, Wilkinson MJ, Lucareli J, Fogler JM, Becker RE, Huntington N. Quantitative evaluation of content and age concordance across devleopmental milestone 
checklists. Journal of Developmental and Behavioral Pediatrics. 2019.

doi:10.1097/DBP.0000000000000695.

87. Zuckerman B. Promoting early literacy in pediatric practice: Twenty years of Reach Out and Read. Pediatrics. 2009;124(6):1660-1665.

88. National Center for Learning Disabilities. Learning Disabilities Checklist. 2014; https://childdevelopmentinfo.com/wp-content/uploads/2014/12/ldchecklist.pdf. Accessed August 1, 2019

89. Kroenke K, Spitzer RL, Williams JB. The patient health questionnaire-2: Validity of a two-item depression screener. Med Care. 2003;41(11):1284-1292.

90. Zimmerman M, Gorlin E, Darlymple KL, Chelminski I. A clinically useful screen for attention-deficit/hyperactivity disorder in adult psychiatric outpatients. Annals of Clinical Psychiatry. 2017;29:160-166.

91. Hutton JS, Justice LM, Huang G, Kerr A, DeWitt T, Ittenbach RF. The Reading House: A children's book for emergent literacy screening during well-child visits. Pediatrics. 2019;143(6):e20183843.

92. Gabrieli J, Gaab N. Early Literacy Assessments. 2019; https://docs.google.com/spreadsheets/d/16m40o49LZ_9wZI9VPAxhHFlATvhSM1mm0oGr48jFfo/edit\#gid=734901246. Accessed August 1, 2019.

93. Institute of Education Sciences. What Works Clearinghouse. 2019; https://ies.ed.gov/ncee/wwc/. Accessed August 1, 2019.

94. Lefly DL, Pennington BF. Reliability and validity of the adult reading history questionnaire. Journal of Learning Disabilities. 2000;33(3):286-296.

95. International Dyslexia Association. Dyslexia screener for adults: Adult reading history questionnaire. 2019; https://dyslexiaida.org/screening-for-dyslexia/dyslexia-screener-foradults/. Accessed August 1, 2019.

96. National Center on Improving Literacy. State of dyslexia. 2019; https://improvingliteracy.org/state-of-dyslexia. Accessed August 1, 2019. 